\title{
Characterization of Arsenic Biotransformation Products from an Open Anaerobic Degradation of Fucus distichus by Hydride Generation Gas Chromatography Atomic Absorption Spectrometry and High Performance Liquid Chromatography Inductively Coupled Plasma Mass Spectrometry
}

\author{
Abiodun A. Ojo and Amos Onasanya \\ Department of Chemical Sciences, Afe Babalola University, PMB, Ado Ekiti 5454, Nigeria \\ Correspondence should be addressed to Abiodun A. Ojo; abeo39@yahoo.com
}

Received 30 August 2013; Accepted 23 September 2013

Academic Editors: J. H. Z. Dos Santos, C. S. Ha, C. Liang, and R. E. Santelli

Copyright (C) 2013 A. A. Ojo and A. Onasanya. This is an open access article distributed under the Creative Commons Attribution License, which permits unrestricted use, distribution, and reproduction in any medium, provided the original work is properly cited.

\begin{abstract}
This work reports on the isolation and determination of biotransformation products obtained from the organoarsenic compounds that are present in Fucus distichus when it was subjected to an open anaerobic decomposition by using the Hydride Generation Gas Chromatography Atomic Absorption Spectrometry (HG-GC-AAS) and High Performance Liquid Chromatography Inductively Coupled Plasma Mass Spectrometry (HPLC-ICP-MS). The seaweed and filtrate residues obtained from the open anaerobic degradation procedure were extracted in methanol and partitioned in phenol-ether-water mixtures to obtain water soluble extracts. The water soluble extracts were cleaned up and separated on a gel permeation Sephadex G15 column. Arsenic species concentrations were determined by using HG-GC-AAS. Final characterization of the biotransformation isolates was carried out on HPLC-ICP-MS. Only two arsenic species, 2-dimethylarsinoyl ethanol (DMAE) and dimethylarsinic acid (DMAA), were positively identified in the water soluble extract of the marine brown algae. The two arsenic species are strong intermediate candidates in the biosynthesis of arsenobetaine from oceanic arsenate in marine food webs.
\end{abstract}

\section{Introduction}

Several species of arsenicals have been characterized in the marine environment, particularly in marine algae and seaweed which are known to concentrate high arsenic contents [1-3]. Some marine macroalgae may contain an appreciable quantity of inorganic arsenic as found in edible seaweed containing up to $50 \%$ of arsenic in the inorganic form [4]. In many studies, however, organic arsenic compounds called arsenosugars are found to be the most predominant arsenicals found in the marine macroalgae [5]. Even though marine macroalgae are at the bottom of the food chain and contain the greatest concentrations of arsenic, evidence revealed that arsenic is not biomagnified by higher organisms in the food chain [6]. Instead of biomagnifications of arsenic as one ascends the trophic levels, only accumulation and or elimination of arsenic occur in marine organism [7]. These arsenicals can be subjected to various biotransformations including reduction, oxidation, and methylation [5].

In the marine environment, biological transformation of arsenic can occur due to either microbial activities or the organism's adaptive response to accumulated arsenic $[7,8]$. The microbial transformations of arsenic can occur via redox transformation between arsenite (AsIII) and arsenate (AsV), as well as through biomethylation of arsenic into volatile methyl arsines. The primary producers, including phytoplankton and macroalgae, accumulate inorganic arsenic, which is then converted or biotransformed into complex organic molecules that are either water- or lipid-soluble arsenic compounds. When these primary producers are fed upon by the higher trophic level, the water- or lipid-soluble organoarsenicals are further metabolized into other distinct arsenicals and /or, likely accumulated and unchanged [5]. 
Algae are a primary accumulator of arsenic in the marine environment and are an important stage of arsenic metabolism through the food chain $[7,9]$. The concentration of arsenic in marine macroalgae is of the same order as in marine animals $\left(\sim 10 \mu \mathrm{gg}^{-1}\right)$ and some $4000-5000$ times the concentration in sea water. In marine organisms, arsenic occurs mainly as nontoxic organic compounds with only small amounts of the inorganic arsenic species present. Arsenobetaine is widely distributed in marine animals at different trophic levels and is considered the end product of arsenic metabolism in marine food chains. Arsenobetaine has been identified in extracts of marine algae [10]. However, the bulk of the arsenic in algae appears to be in the form of dimethyl-(ribosyl)arsine oxides (or arsenosugars) [2, 5]. Previous findings suggested that a microbially mediated stage, probably occurring within sediments, is necessary for the generation of arsenobetaine from arsenoribosides (or arsenosugars) [11].

When Ecklonia radiata (brown kelp) was allowed to decompose anaerobically in the presence of sea water and beach sand, the algal arsenoribosides were quantitatively converted to dimethylarsinoyl ethanol, $\left(\mathrm{CH}_{3}\right)_{2} \mathrm{As}(\mathrm{O}) \mathrm{CH}_{2} \mathrm{CH}_{2} \mathrm{OH}$ (DMAE) [12, 13]. It has been proposed that the dimethyl-(5-ribosyl)arsine oxides and their anaerobic degradation product, DMAE, are the most likely candidates as intermediates for the production of arsenobetaine from oceanic arsenate in marine food webs [13]. However, previous studies have suggested an alternative pathway by which marine organisms can produce arsenocholine by the breakdown of arsenophosphatidyl choline by phospholipases [14]. Arsenocholine, $\left(\mathrm{CH}_{3}\right)_{3} \mathrm{As}^{+} \mathrm{CH}_{2} \mathrm{CH}_{2} \mathrm{OHX}^{-}(\mathrm{X}=\mathrm{Cl}$, I), could then be oxidized to arsenobetaine, $\left(\mathrm{CH}_{3}\right)_{3} \mathrm{As}^{+} \mathrm{CH}_{2} \mathrm{COO}^{-}$ [14]. It remains to be established if arsenobetaine is formed from arsenosugars via the dimethylarsinoyl ethanol (DMAE) intermediate and passed up the food chain or if organisms at different trophic levels have the ability to synthesize arsenobetaine. The debate about the pathway for the biotransformation of arsenic in the marine environment has not been completely resolved $[10,15]$.

Many analytical techniques have been developed for chemical speciation of elements in the environmental samples $[4,5,16]$. During the last two decades substantial progress has been made in incorporating separation methods with powerful detection methods for reliable quantitative measurements [17, 18]. High performance chromatography (HPLC) is one of the most common methods used for separation of nonvolatile analytes and has been extensively coupled with atomic spectroscopy for quantification. In addition, the HPLC separation of arsenic species has been coupled with online microwave digestion and hydride generation to facilitate the direct determination of reducible and nonreducible forms of arsenic [18]. The other convenient method for online coupling is inductively coupled plasma atomic emission spectrometry (ICP-AES), which is sometimes referred to as ICP-Optical Emission Spectrometry (ICP-OES) and inductively coupled plasma mass spectrometry (ICP-MS). ICP-MS has enabled multielemental detection and isotopic discrimination with extremely high sensitivity. Moreover, HPLC and GC were successfully coupled with ICP-MS and now referred to as hyphenated technique for speciation analysis. This technique is now the most frequently used analytical technique for speciation purposes $[5,17,18]$.

For a complete understanding of the bioaccumulation and biotransformation of the arsenic in the marine environment, this paper investigated an open anaerobic decomposition of algal arsenosugars in a Fucus distichus sp. collected from the coast of British Columbia and its decomposition products were characterized and positively identified by using the Hydride Generation Gas Chromatography Atomic Absorption Spectrometry (HG-GC-AAS) and the High Performance Liquid Chromatography combined with Inductively Coupled Plasma Mass Spectrometry (HPLCICPMS). Additionally, this paper contributes to the complete understanding about the pathway for the transformation of arsenic in the marine environment by suggesting that dimethyl arsenic acid, $\left(\mathrm{CH}_{3}\right)_{2} \mathrm{AsO}(\mathrm{OH})(\mathrm{DMAA})$, a product obtained in the open anaerobic decomposition of the Fucus sp., could provide a new mechanism leading to the formation of arsenobetaine, the main organoarsenicals found in marine organisms.

\section{Materials and Methods}

2.1. Samples Collection. Fucus sp. (1.03 kg) was collected fresh from Wreck Beach at Vancouver Point Grey in British Columbia, Canada, at low tide on rocks almost submerged in the early morning cold water.

2.2. Reagents. All chemicals used from $\mathrm{BDH}$, Fisher Scientific, Aldrich, Eastman Kodak, Alfa, and MCIB were classified as analytical grade and meet the American Chemical Society's (ACS) Specifications, respectively. Aqueous stock solutions (1000 ppm of arsenic) of arsenite, arsenate, MMAA, and DMAA were prepared by dissolving appropriate amounts of $\mathrm{As}_{2} \mathrm{O}_{3}(\mathrm{BDH})$, $\mathrm{Na}_{2} \mathrm{HAsO}_{4} \cdot 7 \mathrm{H}_{2} \mathrm{O}$ (MCIB), $\mathrm{CH}_{3} \mathrm{AsO}(\mathrm{ONa})_{2} \cdot 6 \mathrm{H}_{2} \mathrm{O}$ (Alfa), and $\left(\mathrm{CH}_{3}\right)_{2} \mathrm{AsO}(\mathrm{OH})$ (Fisher). Unless otherwise stated, standard solutions were prepared by serial dilution of these stock solutions with deionized water and sodium borohydride (Aldrich) solutions were made fresh in deionized water. The HPLC eluant used in this work is $10 \mathrm{mM}$ tetraethylammonium hydroxide $+4 \mathrm{mM}$ malonic acid $+0.1 \%$ methanol (HPLC grade, Fisher) at $\mathrm{pH} 6.8$. This was prepared in deionized distilled water. The $\mathrm{pH}$ of the HPLC eluant was adjusted by using diluted sodium hydroxide. The solution was subsequently filtered through a $0.45 \mu \mathrm{m}$ membrane filter before use. Other solvents from commercial sources were either of analytical or HPLC grade and used after filtration through millipore $0.45 \mu \mathrm{m}$ membrane filters. All glassware and plastic ware were cleaned by soaking them overnight in $2 \%$ extran solution, rinsing with tap water and soaking in dilute hydrochloric acid overnight. These glass and plastic containers were first rinsed thoroughly using tap water and then deionized water. The stock solutions (1000 ppm of arsenic) arsenobetaine, 
arsenocholine, and tetramethyl arsonium iodide were prepared from synthetic samples by dissolving appropriate amounts of these compounds in $0.01 \mathrm{M}$ hydrochloric acid. $1000 \mathrm{ppm}$ of arsenic stock solution of dimethylarsinoyl ethanol (DMAE) was prepared in deionized water.

\subsection{HG-GC-AAS and HPLC-ICPMS Analytical Procedures.} For the determination of methylated arsenic compounds in the seaweed and filtrates extracts, samples $(0.03-0.17 \mathrm{~g})$ placed directly into separate $40 \mathrm{~mL}$ tall glass test tubes were digested with $5 \mathrm{~mL}$ of $2 \mathrm{M}$ sodium hydroxide. A hot water bath heated to $90-95^{\circ} \mathrm{C}$ by an aluminum heating block was employed for the heating carried out for three hours. On cooling, the digests were neutralized with dilute hydrochloric acid and made up to $40 \mathrm{~mL}$ with deionized water. Arsenic determination and speciation were carried out on the digestates, which in most cases were diluted prior to analysis by the HG-GC-AAS technique [17, 19]. The hydride generation system consists of a peristaltic pump for mixing known volumes of sample (or standard) solutions with $1 \mathrm{M}$ hydrochloric acid and 2\% sodium borohydride. The arsines generated were led through a gas-liquid separator using a helium carrier gas into a moisture Teflon U-trap $(30 \mathrm{~cm}$ length $\times 0.8 \mathrm{~cm}$ i.d.) immersed in a dry ice-acetone slurry and subsequently swept into a hydride trap, a Teflon U-tube $\left(30 \mathrm{~cm}\right.$ length $\times 0.4 \mathrm{~cm}$ i.d.) cooled by nitrogen $\left(-196^{\circ} \mathrm{C}\right)$. The hydride was then warmed by using a water bath $\left(70^{\circ} \mathrm{C}\right)$ and the arsines were liberated and carried onto Porapak-PS column within a Varian Vista 6000 Gas Chromatography (GC). The volatile arsines were separated on the column by using a preset temperature program and detected by passing them into an air-hydrogen flame in a quartz cuvette placed carefully in the light path of an arsenic hollow cathode lamp. Detection of the arsenic absorption was achieved by using an 810 Jarrell-Ash Atomic Absorption Spectrophotometer coupled with a Hewlett Packard 3390A Integrator. Arsenic compounds of known concentrations (10 ppb As(Ill), As(V), MMAA, and 20 ppb DMAA) were used as arsenic standards and their chromatograms were compared with those of the extracts. Normal calibration procedure was used with duplicate determinations carried out on each sample (in most cases, otherwise triplicate analysis was used). The peak area absorbance mode of the AAS was normally utilized with the HG-GC-AAS technique. The experimental and instrumental operating conditions for the HPLC-ICPMS analytical procedures have been previously reported [20]. The HPLC separation (online with the ICPMS) was carried out on an Inertsil ODS-2 $(250 \times 4.6 \mathrm{~mm}$ id, GL Sciences, Japan $)$ HPLC column using $10 \mathrm{mM}$ tetraethylammonium hydroxide $+4 \mathrm{mM}$ malonic acid $+0.1 \%$ methanol at $\mathrm{pH} 6.8$ as the mobile phase. The columns were equilibrated with the appropriate eluant before any sample introduction for at least two hours at $1 \mathrm{~mL} \mathrm{~min}^{-1}$. The flow rate employed was $0.8 \mathrm{~mL} \mathrm{~min}^{-1}$. The seaweed extracts and chromatographic fractions or isolates were centrifuged to remove any suspended particulates prior to ion pair chromatography on the HPLC columns. Identification of arsenic compounds present in the seaweed samples was made by matching and comparing their retention times obtained from the HPLC-ICPMS chromatograms with those of known standards using spiked and/or unspiked arsenic compounds as well as two major arsenic species found in standard reference material, NIST 1566a oyster tissue [16].

2.4. Isolation of Anaerobic Decomposition Products. The procedure [13] involved mixing Fucus sp. (1.03 kg) at room temperature with $2 \mathrm{~L}$ unfiltered seawater and dark sediment $(0.26 \mathrm{~kg})$. The mixture was placed in a sealed plastic container wrapped in aluminum foil and was shaken in the dark for 11 days. To allow for the open anaerobic decomposition condition, the cap of the plastic container was then left opened under the continuous flow of inert argon gas for another 30 days. At the end of 41 days, the smelly mixture was decanted/filtered in order to separate the seaweed/sediment residue from the liquid filtrate. The filtrate after evaporation $(56.21 \mathrm{~g})$ and the seaweed/sediment residue were separately extracted (3 times) in methanol. The filtrate methanol soluble $(33.88 \mathrm{~g})$ and the seaweed/sediment methanol soluble $(29.52 \mathrm{~g})$ extracts were kept, while their methanol insoluble materials discarded off without further analysis. Each of the extracts was subjected to phenol-ether-water partitioning in order to obtain the more polar water layer while discarding the less polar phenol layer. The extract residues were dissolved in deionized water as the water soluble extracts of the filtrate $(30.22 \mathrm{~g})$ and the seaweed $(21.49 \mathrm{~g})$. These water soluble extracts were twice fractionated on a Sephadex G15 gel permeation chromatographic column $(2.5 \mathrm{~cm} \times 65 \mathrm{~cm}$; water as eluant) to obtain two bands for the water soluble filtrate extract at elution volumes $110-408 \mathrm{~mL}$ (filtrate extract 1 ) and 573-964 mL (filtrate extract 2) and also two bands for the water soluble seaweed extract at elution volumes $104-401 \mathrm{~mL}$ (seaweed extract 1) and $550-760 \mathrm{~mL}$ (seaweed extract 2). These close chromatographic fractions suggest that the filtrate and seaweed extracts have similar decomposition products based on size exclusion gel permeation on the Sephadex G15 column.

\section{Results}

The water soluble filtrate and seaweed samples obtained prior to separation on the gel permeation column were subjected to arsenic speciation analysis by using the semicontinuous mode HG-GC-AAS technique (Table 1), before and after subjecting them to a 3-hour hot base digestion.

Prior to the hot base digestion, the seaweed extract was found to contain a total of $5.32 \mu \mathrm{g}$ arsenic with the majority $(3.44 \mu \mathrm{g})$ of it in the dimethylated arsenic species form. This confirms the presence of DMAA in the decomposition product of this Fucus distichus. After the hot base digestion, the total arsenic in the seaweed extract was $15.18 \mu \mathrm{g}$. The percentage of the dimethylated arsenic species prior to the digestion $(22.7 \%)$ compared to $74.7 \%$ after the hot base digestion confirms the presence of "hidden arsenic" species. Similarly, the filtrate extract contained mainly the dimethylated arsenic species prior to $(5.55 \mu \mathrm{g}$ DMAA; $6.88 \mu \mathrm{g}$ total As) and after (9.93 $\mu \mathrm{g}$ DMAA; $11.43 \mu \mathrm{g}$ total As) the hot base 
TABLE 1: Arsenic speciation in the anaerobic decomposition products of $F$. distichus by the semicontinuous mode HG-GC-AA analysis.

\begin{tabular}{|c|c|c|c|c|c|c|c|c|c|}
\hline \multirow{3}{*}{ Number } & \multirow{3}{*}{$\begin{array}{c}\text { Open anaerobic } \\
\text { decomposition extract }\end{array}$} & \multicolumn{8}{|c|}{ 3-hour hot base digestion ( $2 \mathrm{M} \mathrm{NaOH}, 5 \mathrm{~mL})$} \\
\hline & & \multicolumn{4}{|c|}{ Arsenic before digestion (in $\mu \mathrm{g}$ ) } & \multicolumn{4}{|c|}{ Arsenic after digestion (in $\mu \mathrm{g}$ ) } \\
\hline & & Inorg. As & MMAA & DMAA & Total As & Inorg. As & MMAA & DMAA & Total As \\
\hline 1 & Seaweed & 1.88 & $\mathrm{~d}$ & 3.44 & 5.32 & 3.84 & $\mathrm{~d}$ & 11.34 & 15.18 \\
\hline 2 & Filtrate & 1.33 & $\mathrm{~d}$ & 5.55 & 6.88 & 1.50 & $\mathrm{~d}$ & 9.93 & 11.43 \\
\hline
\end{tabular}

d: detected; Inorg. As: inorganic arsenic; MMAA: monomethylarsonic acid; DMAA: dimethylarsinic acid.

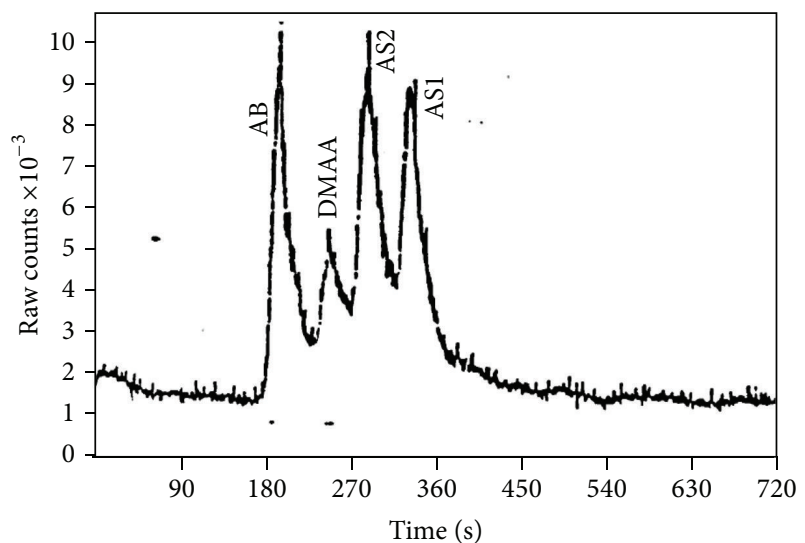

Figure 1: HPLC-ICPMS chromatogram of the NIST 1566a oyster tissue extract.

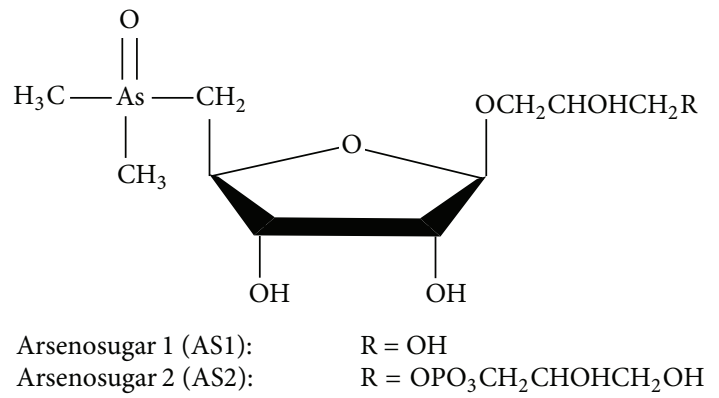

FIGURE 2: Arsenosugars (AS1 and AS2) found in NIST 1566a oyster tissue.

digestion. Also, prior to characterization on the HPLC-ICPMS of the Sephadex G15 column chromatographic isolates, the total arsenic in the filtrate extract and seaweed extract were determined: $7.89 \mu \mathrm{g}$ As, filtrate extract 1 and $3.54 \mu \mathrm{g}$ As, filtrate extract 2; $10.78 \mu \mathrm{g}$ As, seaweed extract isolate 1 and $4.40 \mu \mathrm{g}$ As, seaweed isolate 2 .

Two standard samples were used for retention times comparison. These are a reference material NIST 1566a oyster tissue and a standard dimethylarsinoyl ethanol synthesized for this study. The HPLC-ICPMS chromatogram for the NIST 1566a oyster tissue extract is shown in Figure 1.

The four arsenic species, arsenobetaine (AB), dimethylarsinic acid (DMAA, retention times $230 \mathrm{~s}-275 \mathrm{~s}$ ), and arsenosugars AS1 and AS2 (Figure 2), were identified and used as standards in this study.

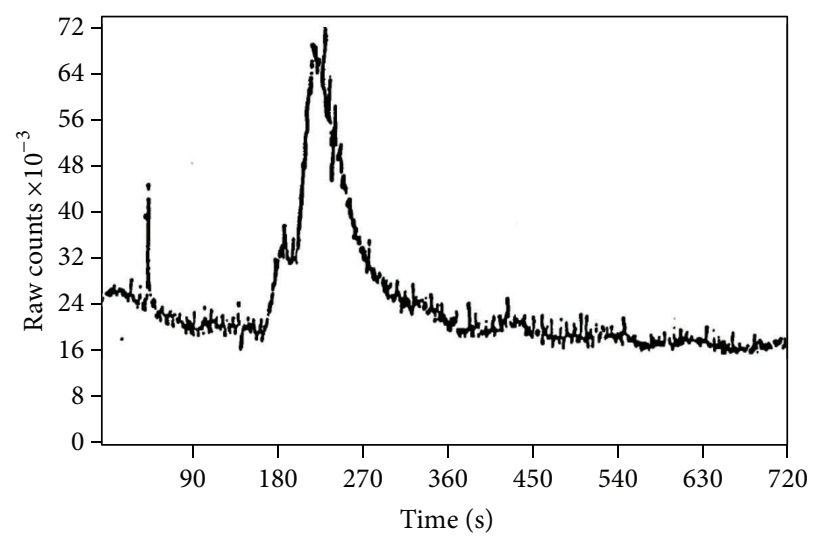

Figure 3: HPLC-ICPMS chromatogram of DMAE (0.78 ppm As).

The synthetic product was characterized to be dimethylarsinoyl ethanol (DMAE) by using Desorption Chemical Ionization Mass Spectrometry (DCIMS), ${ }^{1} \mathrm{H}$ - and ${ }^{13} \mathrm{C}-\mathrm{NMR}$. The characteristic mass peaks at $(\mathrm{M}+\mathrm{l})$ (or protonated molecular ion) $\mathrm{m} / z$ (76.04\%) 167 , base peak $(\mathrm{M}-\mathrm{OH}) \mathrm{m} / \mathrm{z}$ (100\%) 149 and $\mathrm{m} / z$ (trace) $106\left(\mathrm{M}^{+}-\mathrm{CH}_{3} \mathrm{CH}_{2} \mathrm{CH}_{2} \mathrm{OH}\right)$ were observed in the DCIMS spectrum of the synthetic product. The ${ }^{1} \mathrm{H}$ NMR spectrum showed chemical shifts $\delta(\mathrm{ppm})$ at 2.27 (s) for two methyl groups attached to arsenic, $\left(\mathrm{CH}_{3}\right)_{2} \mathrm{As}$; $2.97(\mathrm{t}), \mathrm{CH}_{2} \mathrm{As} ; 4.40(\mathrm{t}), \mathrm{CH}_{2} \mathrm{OH}$; and $4.72(\mathrm{~s}), \mathrm{H}_{2} \mathrm{O}$. The ${ }^{13} \mathrm{C}$ NMR spectrum revealed chemical shifts $\delta(\mathrm{ppm})$ at 16.74 for the two methyl groups attached to arsenic, $\left(\mathrm{CH}_{3}\right)_{2} \mathrm{As}$; 35.26, $\mathrm{CH}_{2} \mathrm{As}$; and $57.16 \mathrm{ppm}, \mathrm{CH}_{2} \mathrm{OH}$. The HPLC-ICPMS chromatogram of DMAE is shown in Figure 3 where DMAE is the major peak eluting between $194 \mathrm{~s}$ and $395 \mathrm{~s}$.

The following HPLC-ICPMS chromatograms were obtained for the water soluble seaweed filtrates 1 and 2 (Figures 4 and 5) and also, for a 1:3 mixture of seaweed isolates 1 and 2 (Figure 6).

\section{Discussion}

The seaweed extract contains $65 \%$ of its total arsenic as "hidden" arsenic species that are most likely arsenosugars previously determined [20]. The four arsenic species, arsenobetaine $(\mathrm{AB})$, dimethylarsinic acid (DMAA, retention times $230 s-275 s$ ), and arsenosugars $A$ and $B$, were identified and used as standards in this study $[16,20]$. The chromatogram obtained for the water soluble seaweed isolate 1 revealed one arsenic containing band whose retention times (194 s395 s) matched that of dimethylarsinylethanol (DMAE). This 


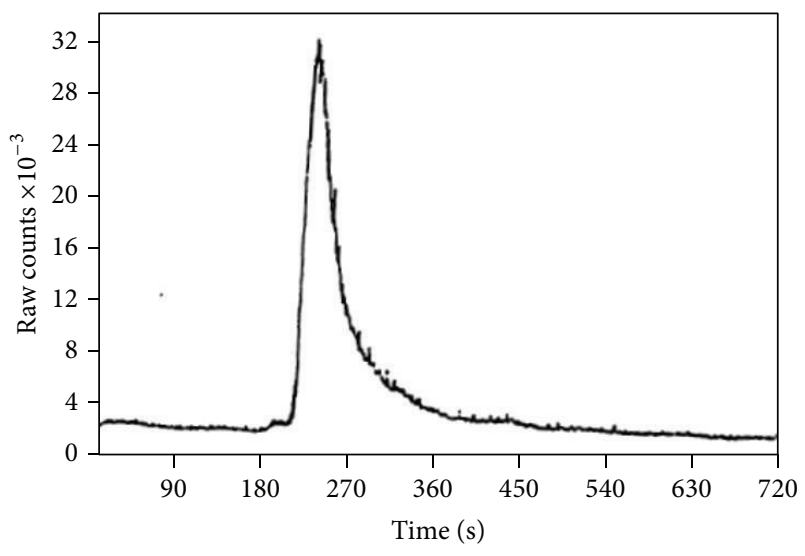

FIGURE 4: HPLC-ICPMS chromatogram of seaweed isolate 1 from the anaerobic decomposition of $F$. distichus.

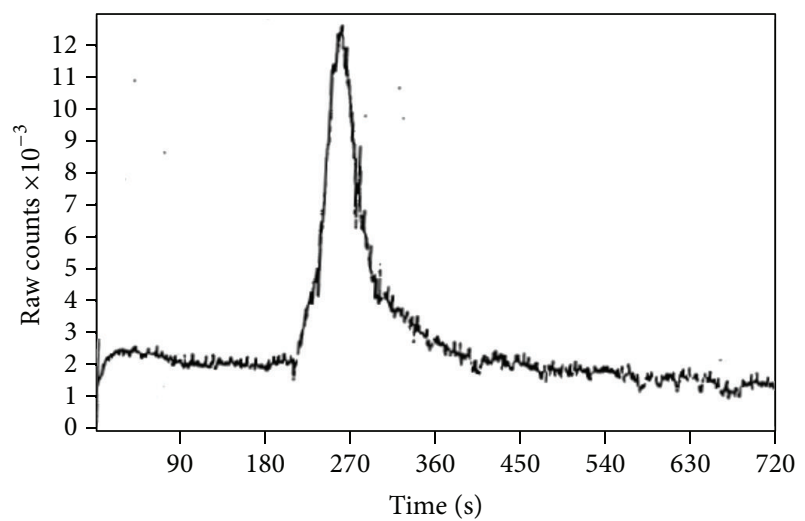

FIGURE 5: HPLC-ICPMS chromatogram obtained for the seaweed isolate 2 .

seaweed isolate 1 is dimethylarsinylethanol on the basis of the retention time on the HPLC-ICPMS system. This conclusion has also been made with the isolated decomposition compound obtained from water soluble seaweed fraction in the anaerobic decomposition of Ecklonia radiata $[12,13]$.

Further, on the basis of retention times, the arsenic containing seaweed isolate 2 was found to be similar to that of dimethylarsinic acid (retention times $230 \mathrm{~s}-275 \mathrm{~s}$ matched with chromatogram of DMAA). On the basis of retention times, the water soluble seaweed isolate 2 is dimethylarsinic acid. When the seaweed isolates 1 and 2 were mixed $(1: 3)$, the retention time of this mixture did not match either DMAE or DMAA individually but overlaps the profile of the two compounds. This serves to confirm that these two arsenicals are separate components of the decomposition products of $F$. distichus. In a previous work when samples of the brown alga Ecklonia radiata, which contains three major arsenosugars, were allowed to naturally decompose under moist conditions and analyzed by HPLC/ICPMS following an aqueous methanol extraction, the original arsenosugars were found to have degraded primarily to arsenate via two major intermediates dimethylarsinoyl ethanol (DMAE) and dimethylarsinic acid (DMAA) [12]. By using the gel

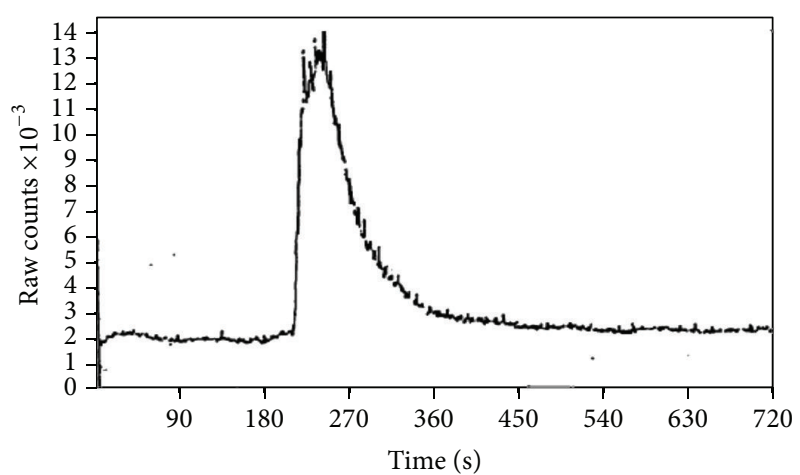

FIGURE 6: Chromatogram obtained with a mixture (1:3) of seaweed isolates 1 and 2 from the anaerobic decomposition of $F$. distichus.

permeation elution volumes, as well as the HPLC-ICPMS chromatograms of filtrate isolates 1 and 2, found to be similar to those of seaweed isolates 1 and 2, these decomposition products were identified to be DMAE and DMAA, respectively. Following the isolation of DMAE from the decomposition product of Ecklonia radiata, it has been suggested that DMAE occupies a key position in the biosynthesis of arsenobetaine $[12,21]$. Similarly, it has been proposed in metabolic pathways involving arsenic in its biotransformation in the ecosystem that DMAA is an important arsenical that can be converted to arsenobetaine in marine organism $[12,15]$. This study having identified both DMAE and DMAA in the open anaerobic decomposition products of Fucus distichus of British Columbia, Canada, supports the view that DMAE and DMAA are important intermediates in the biotransformation to and the biosynthesis of arsenobetaine in the higher trophic level.

\section{Conclusions}

In this open anaerobic decomposition study, both DMAE and DMAA have been identified as anaerobic decomposition products of $F$. distichus by using HG-GC-AAS and HPLCICP-MS techniques. The study contributes evidence supporting both DMAE and DMAA as key intermediates for the production of arsenobetaine. Possible pathway involving DMAA like the one previously proposed for DMAE may suggest new mechanism leading to the formation and accumulation of arsenobetaine in the higher trophic levels.

\section{Acknowledgments}

The author appreciates the financial support provided by the Natural Sciences and Engineering Research Council of Canada. The analytical support of Dr. Xiao Chun Lee for the HPLC-ICPMS was appreciated.

\section{References}

[1] Y. Nakajima, Y. Endo, Y. Inoue et al., "Ingestion of Hijiki seaweed and risk of arsenic poisoning," Applied Organometallic Chemistry, vol. 20, no. 9, pp. 557-564, 2006. 
[2] A. Price, W. Maher, J. Kirby et al., "Distribution of arsenic species in an open seagrass ecosystem: relationship to trophic groups, habitats and feeding zones," Environmental Chemistry, vol. 9, no. 1, pp. 77-88, 2012.

[3] W. Baeyens, A. D. Brauwere, N. Brion, M. D. Gieter, and M. Leermakers, "Arsenic speciation in the River Zenne, Belgium," Science of the Total Environment, vol. 384, no. 1-3, pp. 409-419, 2007.

[4] Y. Shimoda, Y. Suzuki, Y. Endo et al., "Speciation analysis of arsenics in commercial Hijiki by high performance liquid chromatography-tandem-mass spectrometry and high performance liquid chromatography-inductively coupled plasma mass spectrometry," Journal of Health Science, vol. 56, no. 1, pp. 47-56, 2010.

[5] K. A. Francesconi and D. Kuehnelt, "Determination of arsenic species: a critical review of methods and applications, 20002003," Analyst, vol. 129, no. 5, pp. 373-395, 2004.

[6] D. Thomson, W. Maher, and S. Foster, "Arsenic and selected elements in inter-tidal and estuarine marine algae, south-east coast, NSW, Australia," Applied Organometallic Chemistry, vol. 21, no. 6, pp. 396-411, 2007.

[7] K. A. Francesconi, "Arsenic species in seafood: origin and human health implications," Pure and Applied Chemistry, vol. 82, no. 2, pp. 373-381, 2010.

[8] R. N. Ratnaike, "Acute and chronic arsenic toxicity," Postgraduate Medical Journal, vol. 79, no. 933, pp. 391-396, 2003.

[9] Y. Nakajima, Y. Endo, Y. Inoue et al., "Ingestion of Hijiki seaweed and risk of arsenic poisoning," Applied Organometallic Chemistry, vol. 20, no. 9, pp. 557-564, 2006.

[10] V. Nischwitz and S. A. Pergantis, "First report on the detection and quantification of arsenobetaine in extracts of marine algae using HPLC-ES-MS/MS," Analyst, vol. 130, no. 10, pp. 13481350, 2005.

[11] J. Borak and H. D. Hosgood, "Seafood arsenic: implications for human risk assessment," Regulatory Toxicology and Pharmacology, vol. 47, no. 2, pp. 204-212, 2007.

[12] A. W. Ritchie, J. S. Edmonds, W. Goessler, and R. O. Jenkins, "An origin for arsenobetaine involving bacterial formation of an arsenic-carbon bond," FEMS Microbiology Letters, vol. 235, no. 1, pp. 95-99, 2004.

[13] J. S. Edmonds, K. A. Francesconi, and J. A. Hansen, "Dimethyloxarsylethanol from anaerobic decomposition of brown kelp Ecklonia radiata: a likely precursor of arsenobetaine in marine fauna," Experientia, vol. 38, no. 6, pp. 643-644, 1982.

[14] D. J. H. Phillips and M. H. Depledge, "Metabolic pathways involving arsenic in marine organisms: a unifying hypothesis," Marine Environmental Research, vol. 17, no. 1, pp. 1-12, 1985.

[15] J. Kirby, W. Maher, and D. Spooner, "Arsenic occurrence and species in near-shore macroalgae-feeding marine animals," Environmental Science and Technology, vol. 39, no. 16, pp. 59996005, 2005.

[16] C.-F. Yeh and S.-J. Jiang, "Speciation of arsenic compounds in fish and oyster tissues by capillary electrophoresis-inductively coupled plasma-mass spectrometry," Electrophoresis, vol. 26, no. 7-8, pp. 1615-1621, 2005.

[17] V. L. Rajaković, N. Ž. Todorović, V. N. Rajaković-Ognjanović, and A. E. Onjia, "Analytical methods for arsenic speciation analysis," Journal of the Serbian Chemical Society, 2013.

[18] H. Adamu, L. Luter, M. M. Lawan, and B. A. Umar, "Chemical speciation: a strategic pathway for insightful risk assessment and decision making for remediation of toxic metal contamination," Environment and Pollution, vol. 2, no. 3, pp. 92-99, 2013.
[19] K. J. Reimer, "The methylation of arsenic in marine sediments," Applied Organometallic Chemistry, vol. 3, pp. 475-490, 1989.

[20] C. F. Harrington, A. A. Ojo, V. W.-M. Lai, K. J. Reimer, and W. R. Cullen, "The identification of some water soluble arsenic species in the marine brown alga fucus distichus," Applied Organometallic Chemistry, vol. 2, pp. 91-94, 1997.

[21] J. Navratilova, G. Raber, S. J. Fisher, and K. A. Francesconi, "Arsenic cycling in marine systems: degradation of arsenosugars to arsenate in decomposing algae, and preliminary evidence for the formation of recalcitrant arsenic," Environmental Chemistry, vol. 8, no. 1, pp. 44-51, 2011. 

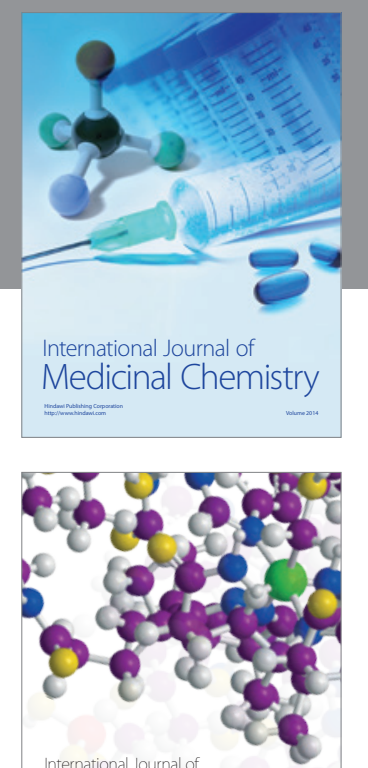

\section{Carbohydrate} Chemistry

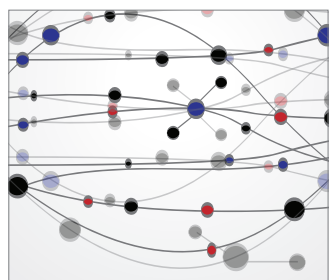

The Scientific World Journal
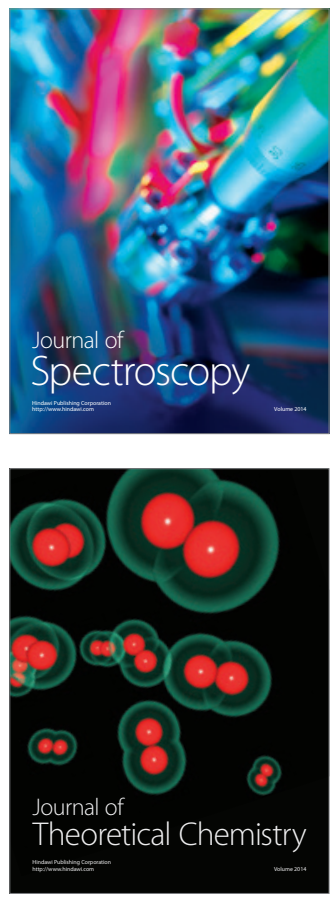
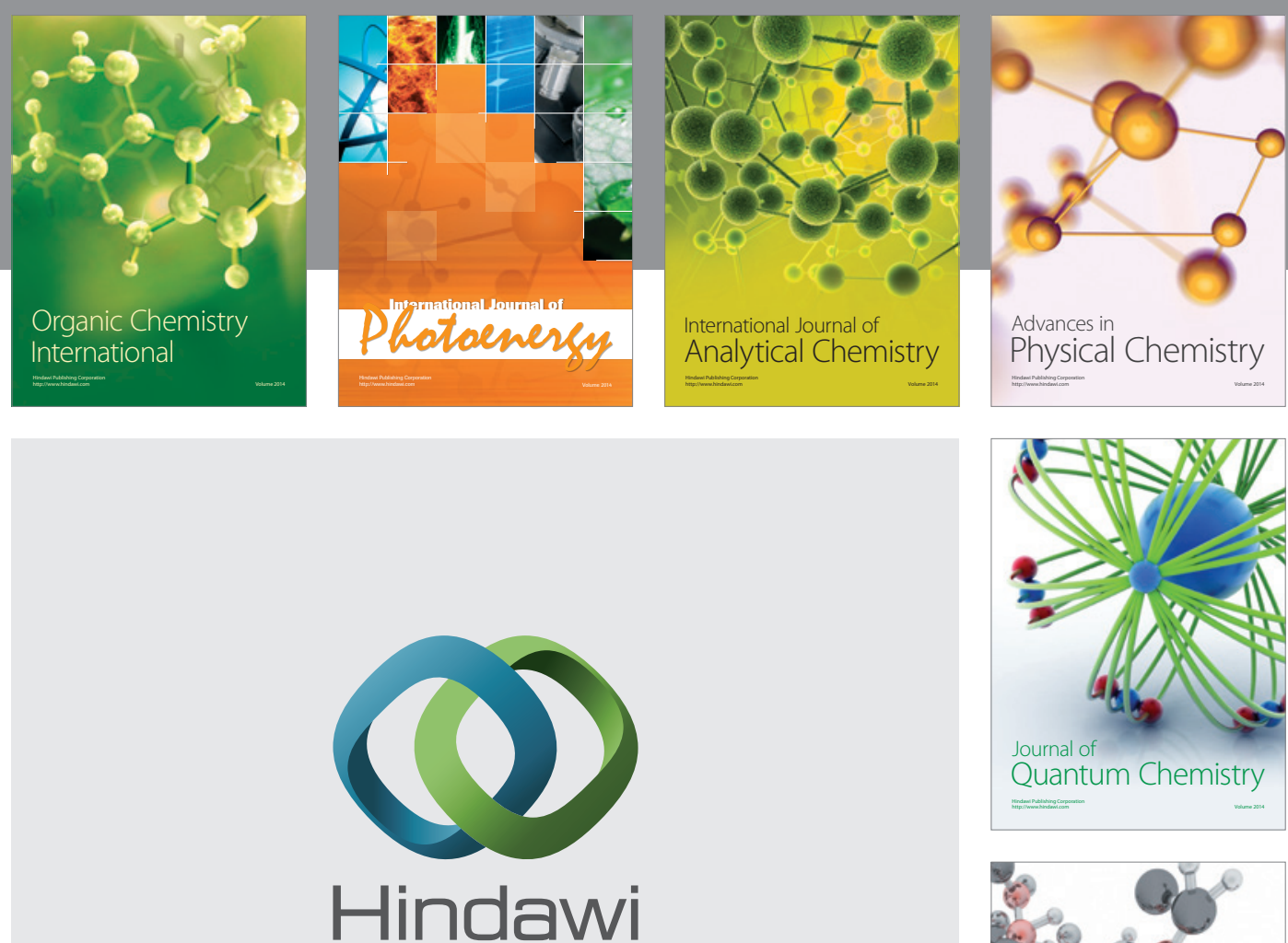

Submit your manuscripts at

http://www.hindawi.com

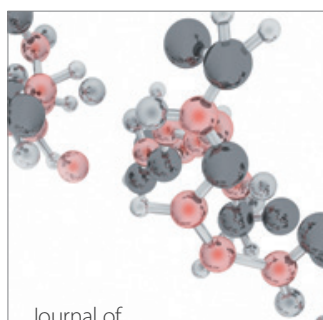

Analytical Methods

in Chemistry

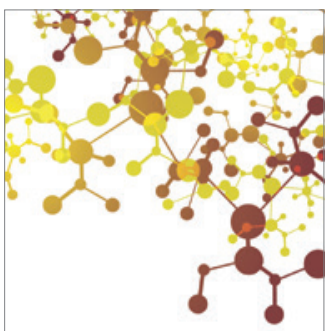

Journal of

Applied Chemistry

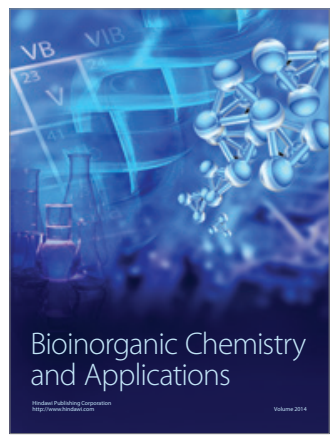

Inorganic Chemistry
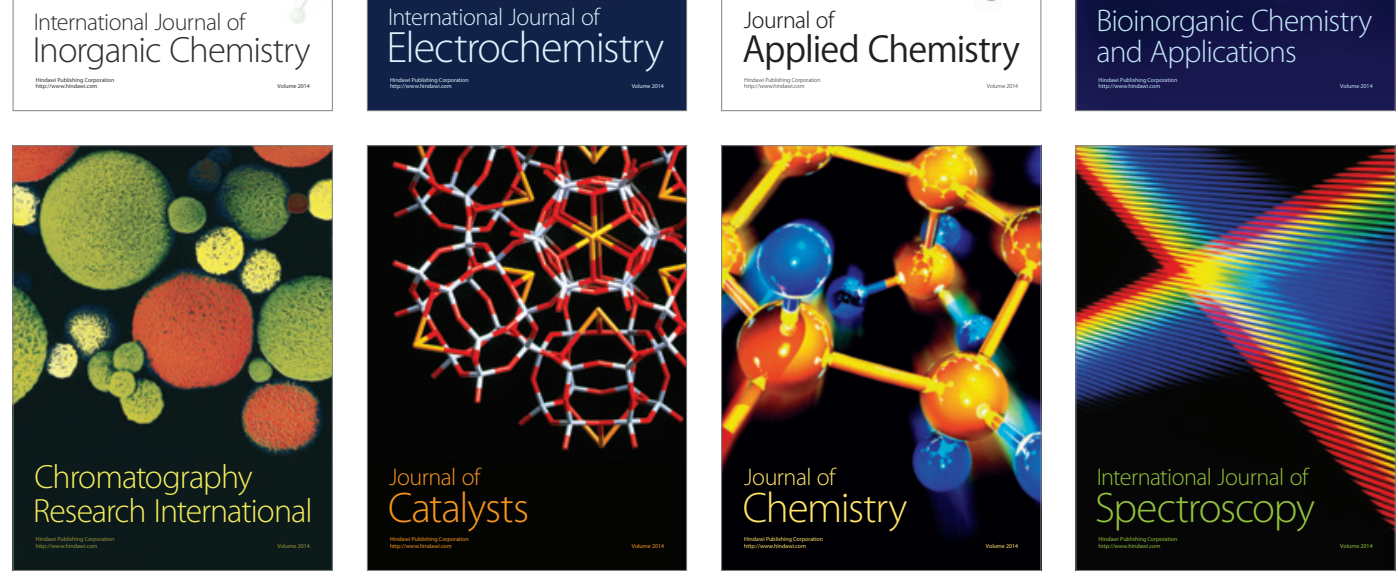